\title{
TOBACCO CONTROL IN NSW : EVIDENCE SUPPORTING IMPROVED STRATEGIES TO REDUCE EXPOSURE TO ENVIRONMENTAL TOBACCO SMOKE
}

\author{
Elayne Mitchell and John Sanders \\ Tobacco and Health Branch \\ NSW Department of Health
}

Environmental tobacco smoke (ETS) is a mixture of sidestream smoke (emitted to the atmosphere from the tip of a burning cigarette) and mainstream smoke (inhaled and exhaled by a smoker). ETS contains at least 50 chemicals recognised to be carcinogenic, as well as thousands of other chemicals including many known to be developmental, reproductive, mutagenic, and cardiac toxins. ${ }^{1,2,3}$ Tobacco smoke is classified as a Group A carcinogen by the United States Environmental Protection Authority, ${ }^{4}$ and is classified as a Group 1 carcinogen (that is, a carcinogen that has been proven to cause cancer in humans) by the International Agency for Research on Cancer. ${ }^{21}$ Many compounds found in ETS are banned or regulated as occupational carcinogens, including arsenic, benzene, and vinyl chloride. ${ }^{3}$ The already extensive evidence of harm to the health of non-smokers who are exposed to ETS continues to mount. Reviews of the epidemiological evidence consistently confirm an association between exposure to ETS and passive smoking and the development of lung cancer, heart disease, and respiratory illness in non-smokers. . $^{1,5,6,7,8,9}$

NSW has comprehensive legislation in place to minimise ETS-related harm in the community. The Occupational Health and Safety Act 2000 requires all employers to ensure the health, safety, and welfare of their employees, consequently preventing smoking in workplaces. The Smoke-Free Environment Act 2000, which banned smoking in enclosed public places in NSW, was a major step forward in public health and reduced ETS exposure in restaurants, shopping centres, and other public places. Since September 2001, all table service dining areas of licensed hotels, licensed nightclubs, and registered clubs, have also been required to be smoke-free. This article presents some of the evidence that supports improved strategies to reduce exposure to environmental tobacco smoke. It also includes a description of the NSW Tobacco Action Plan (page 217), ${ }^{10}$ which outlines further areas for action to ensure that no-one is still exposed to ETS in the workplace.

\section{AN ESTABLISHED HAZARD}

A meta-analysis of the occupational risk to non-smokers of lung cancer from ETS concluded that there is a significant excess risk from occupational exposure to ETS. ${ }^{7}$ A review of hospitality employee exposure to ETS estimated that bar workers are exposed to 4.4 times the ETS experienced in domestic settings. ${ }^{11}$ Cotinine, a chemical that is made by the body from nicotine, is a reliable biochemical marker of exposure to nicotine.
Measurement of cotinine levels in non-smokers is a valid and objective indicator of passive exposure to tobacco smoke, which permits estimation of risks to health. A recent New Zealand study of the exposure of hospitality workers to environmental tobacco smoke reported a clear association between changes in cotinine concentration during work and the workplace smoking policy. ${ }^{12}$ Workers in premises permitting customer smoking reported a higher prevalence of respiratory symptoms and had higher concentrations of cotinine in saliva, compared to those from smoke-free workplaces. Further research on cotinine levels in non-smoking hospitality workers in NSW is needed.

In many settings throughout the world, rather than prohibiting smoking throughout premises, authorities have specified that smoking should not occur in particular places within these premises. This policy is attractive to some who perceive a prohibition on smoking to be a liability. However, evidence suggests that the protection provided by this approach is not comprehensive. An analysis by Repace et al. based on average number of smokers, number of cigarettes smoked, and room size, determined that ETS cannot be controlled by ventilation, air cleaning, or spacial separation. ${ }^{3}$ To achieve the minimum risk using ventilation alone would require, they concluded: 'in excess of one hundred thousand cubic feet per minute per occupant, which would need tornado-like levels of air-flow to achieve' ${ }^{3}$ Consequently, attempts to separate indoor areas in hospitality venues into 'smoking' and 'non-smoking' areas are rarely effective, due to inherent difficulties in preventing the spread of smoke through air-conditioning and doorways.

\section{INADEQUATE ACTION}

In NSW, over recent years, a number of clubs and some hotels have voluntarily introduced smoke-free areas and auditoriums, and this has contributed to a reduction in ETS exposure for patrons and staff in those areas. Patrons can choose to utilise the smoke-free areas, but this same choice is not extended to employees who have to work in smoking sections. These workers may be exposed to high levels of ETS, if there is a concentration of smokers in areas where smoking is permitted. In 1999, a random sample of managers of registered clubs in NSW was surveyed regarding the smoking restrictions in clubs. Fifty-nine per cent reported that most or all of their staff were exposed to tobacco smoke at work, 43 per cent reported having no smoke-free areas, and more than two-thirds reported being concerned about litigation by patrons or staff for damage to health caused by passive smoking. ${ }^{13}$ 
The finding in the case of Marlene Sharp v. Port Kembla $R S L C l u b$ represents an important international precedent as the first case of cancer of the larynx proven at law to be attributed to passive smoking in the workplace. ${ }^{14}$ It would be reasonable for the community to expect-in the face of the mounting medical, scientific, and legal evidencethat clubs and hotels would move swiftly toward voluntary self-regulation. However, in the more than 18 months since the court decision, the industry's voluntary progress toward smoke-free licensed premises has been piecemeal. Australian employers whose workers continue to be regularly exposed to tobacco smoke in their workplace must seriously consider the potential consequences of inaction, as permitting smoking indoors leaves employers exposed to potential litigation.

\section{COMMUNITY SUPPORT}

A recent National Drug Strategy Household Survey estimates that the vast majority ( $>80$ per cent) of the Australian population are non-smokers..$^{15}$ In the 1997 NSW Health Survey, respondents were asked about their attitude toward smoking in registered clubs, hotels, and bars. Over 90 per cent of respondents stated that smoking should either not be allowed or should only be allowed in special areas in registered clubs, and almost 85 per cent believed the same should apply to hotels and bars. ${ }^{16}$ The tobacco industry has engaged in intentional misrepresentation of the scientific evidence around passive smoking, ${ }^{17,18}$ by actively promoting fear of economic consequences for the hospitality industry as a result of tougher restrictions on smoking. International evidence refutes this claim, with numerous studies confirming community support for smoking restrictions, and that patronage and revenues were either maintained or increased. ${ }^{3,5,19,20}$

\section{CONCLUSION}

There is overwhelming evidence of the risks to health caused by exposure to ETS. There is continuing involuntary workplace exposure to ETS among employees of licensed premises. A high level of support exists in the community for the introduction of further restrictions on smoking in clubs and hotels. There is no evidence to support tobacco company predictions regarding the economic outcomes for the hospitality industry as a result of further restrictions. The hospitality industry, the unions, and the community, have an opportunity to work together to ensure that no worker experiences involuntary ongoing exposure to tobacco smoke in their workplace, or has to make a choice to risk their health to earn a living. From a public health perspective, the elimination of exposure to ETS is achievable.

\section{REFERENCES}

1. National Health and Medical Research Council The Health Effects of Passive Smoking-A Scientific Information Paper. Canberra: Commonwealth of Australia, 1997.

2. Skolnick A. Draft of report on second hand smoke released. JAMA 1997; 277(13): 1026-1027.
3. Repace J, Kawachi I, Glantz S. UICC Fact sheet on secondhand smoke. Proceedings, 2nd European Conference on Tobacco or Health, Canary Islands 23-27 February 1999.

4. United States Environmental Protection Agency. Respiratory health effects of passive smoking: Lung cancer and other disorders. Publication EPA/600/6-90/006F. Washington DC: United States EPA, 1992.

5. The Cancer Council NSW. When smoke gets in your eyes ... nose, throat, lungs, and bloodstream. A guide to passive smoking and the law in NSW. Sydney The Cancer Council NSW, 2001.

6. Taylor R, Cumming R, Woodward A, Black M. Passive smoking and lung cancer: A cumulative meta-analysis. Aus N Z J Public Health 2001; 25(3): 203-211.

7. Brown KG. Lung cancer and environmental tobacco smoke: Occupational risk to non-smokers. Environ Health Perspect 1999; 107(S-6): 879-83.

8. Zhong L, Goldberg MS, Parent ME, Hanley JA. Exposure to environmental tobacco smoke and the risk of lung cancer: A meta analysis. Lung Cancer 2000; 27(1): 3-18.

9. He J, Vupputuri S, Allen K, Prerost M, Hughes J, Whelton G. Passive smoking and the risk of coronary heart diseaseA meta-analysis of epidemiologic studies. NEngl J Med 1999; 340(12): 920-926.

10. NSW Department of Health. NSW Tobacco Action Plan 2001-2004. Sydney: NSW Department of Health, 2001.

11. Seigel M. Involuntary smoking in the restaurant workplace: A review of employee exposure and health effects. JAMA 1993; 270(4): 490-493.

12. Bates MN, Fawcett J, Dickson S, Berezowski R, Garret N. Exposure of hospitality workers to environmental tobacco smoke. Tobacco Control 2002 11(2): 125-9.

13. Muscatello D, Rissel C, Ward J. Smoking restrictions in New South Wales registered clubs: Current status and factors associated with high levels of restriction. Health Promotion Journal of Australia 2002; 13(1): 39-43.

14. Stewart B. Semmler P. Sharp v. Port Kembla RSL club: Establishing causation of laryngeal cancer by environmental tobacco smoke. Med J Aust 2002; 176(3): 113-116.

15. Australian Institute of Health and Welfare 2001. National Drug Strategy Household Survey Drug Statistics Series No. 9. Available at www.aihw.gov.au/publications/phe/ ndshs01/index.html.

16. Epidemiology and Surveillance Branch. NSW Health Surveys 1997 and 1998 (HOIST). Sydney: NSW Department of Health, 2000.

17. Hirschhorn N, Bialous S. Second hand smoke and risk assessment: What was in it for the tobacco industry? Tobacco Control 2001; 10: 375-382.

18. Dearlove JV, Bialous SA, Glantz SA. Tobacco industry manipulation of the hospitality industry to maintain smoking in public places. Tobacco Control 2002; 11(2): 94-104.

19. Chapman S, Borland R, Lal A. Has the ban on smoking in New South Wales restaurants worked? A comparison of restaurants in Sydney and Melbourne. Med J Aus 2001; 174(10):512-5.

20. Scollo M, Lal A. Summary of Studies Assessing the Economic Impact of Smoke-Free Policies in the Hospitality Industry. Melbourne: VicHealth Centre for Tobacco Control, 2002. Available online at www.vctc.org.au/tc-res/Hospitality summary.pdf.

21. International Agency for Research on Cancer. IARC Monographs on the Evaluation of Carcinogenic Risks to Humans. IARC monographs may be located at http:// monographs.iarc.fr. $\mathrm{H}$ 


\section{THE NSW TOBACCO ACTION PLAN 2001-2004}

The NSW Tobacco Action Plan 2001-2004 sets out the NSW Government's commitment to the prevention and reduction of tobacco-related harm in New South Wales. The Plan follows the successful NSW Tobacco and Health Strategy 1995-1999. It features a comprehensive range of strategies developed in response to the National Tobacco Strategy 1999-2003, which establishes a coordinated response for tobacco control by state, territory, and Commonwealth governments throughout Australia.

The goal of the Plan is to improve the health of the people of NSW by eliminating or reducing their exposure to tobacco in all its forms. The main objectives of the Plan are to:

- prevent the uptake of tobacco use in non-smokers, especially children and young people;

- reduce the number of users of tobacco products;

- reduce exposure to tobacco smoke;

- decrease the number of deaths and level of disease caused by smoking;

- decrease the economic cost of tobacco related illness.

The Plan has six areas of focus, which are in line with the key strategy areas of the National Tobacco Strategy, outlined below:

\section{Focus 1: Community awareness and education}

- implementation of public education campaigns

- establishment of the NSW Tobacco Control Network

- staff education and training

\section{Focus 2: Smoking cessation}

- continuation and enhancement of Quitline services

- training of health professionals

- incorporating routine delivery of treatment of nicotine dependence into patient care

\section{Focus 3: Availability and supply of tobacco products}

- continuation of Tobacco Sales to Minors prevention program

- enhanced enforcement of tobacco related legislation

- review of the tobbaco control provisions of the NSW Public Health Act 1991

\section{Focus 4: Marketing and promotion of tobacco}

- implementation of tobacco advertising legislation

\section{Focus 5: Tobacco product regulation}

- collaboration with the Commonwealth government to develop a framework for the regulation of tobacco and nicotine products

\section{Focus 6: Exposure to environmental tobacco smoke}

- implementation of smoke-free public places legislation and the NSW Health Smoke Free Workplace Policy

- strategies to address exposure to environmental tobacco smoke in children.

Reducing smoking rates in the community will reduce death, disease, and associated health costs, and is therefore a major priority within the Plan. Specific strategies to target priority areas and population groups will be implemented. These population groups are:

- children and young people;

- Aboriginal and Torres Strait Islander communities;

- non-English speaking background communities with high smoking rates;

- people with a mental illness.

For further information about the NSW Tobacco Action Plan 2001-2004, contact the Tobacco and Health Branch on telephone (02) 93919111 . The Branch is responsible for the statewide coordination of a range of programs aimed at reducing the harm associated with tobacco use. The Plan can be downloaded from the NSW Department of Health website at www.health.nsw.gov.au. Printed copies can be obtained by contacting the Better Health Centre on (02) 98790443.

For further information and support with quitting smoking, call the Quitline on 131848 for the cost of a local call from anywhere in NSW. Quitline is a free 24 hour service. 